\title{
Reliving the day
}

There's a general hum on the wards:

Beeps, bells and buzzers

Mixed with carts rolling, drawers opening and

Voices helping.

An occasional delirious, "Nurse!"

Rings out, followed by

A soothing reassurance.

It's a measured calm, a sensation of

Welcome.

Without warning a chasm opens wide around us,

The air from our lungs sucked into its depths.

Panicked shouts are followed by

Overhead pleas;

The mood turns tense with the electricity of

Fear.

Runners pass by, ruffling onlookers' hair

With their breeze, like the

Breath that is missing.

A frenzied pace settles in

Along with a desperate hush.

The chaos turns into a

Resolute cycle of, " $1,2,3,4 \ldots$...

As breaths are squeezed and elixirs infused.

10, 20, 30, 40 minutes tick by and

The silence is peppered only with orders.

The silence is deafening;

The anticipation, immense.

At once the quiet is shattered;

Not by noise, but by movement.

People walk slowly away,

Shoulders slumped and hopes dashed.

Beeps, buzzers and bells begin again,

No longer muted from the urgency.

Carts start to roll, and

As the chasm slams shut,

The sobbing begins.

\section{Jacqueline Darcey}

Correspondence to Jacqueline Darcey, Morristown Medical Center, Department of Medicine, 100 Madison Avenue, Interoffice Mail \#96, Morristown, New Jersey, USA; jacqueline.darcey@atlantichealth.org

Competing interests None.

Provenance and peer review Not commissioned; internally peer reviewed.

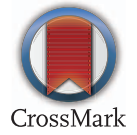

To cite Darcey J. Med Humanit 2017;43:e13.

Published Online First 29 November 2016

Med Humanit 2017;43:e13. doi:10.1136/medhum-2016-011127 